\title{
Raízes Históricas e Epistemológicas da Ontopsicologia
}

\author{
Erico de Lima Azevedo ${ }^{1}$
}

\begin{abstract}
Resumo: Este artigo tem por objetivo analisar as origens históricas e raízes epistemológicas do método ontopsicológico. Foi elaborado por meio de uma revisão bibliográfica com destaque para obras de Edmund Husserl e seus comentadores, bem como de outros filósofos pós-husserlianos. Em um primeiro momento foi apresentada a relevância do estudo do método ontopsicológico para a teoria do conhecimento e para a inovação dos métodos clínicos contemporâneos. A seguir, foi analisado o percurso histórico-teleológico feito por Edmund Husserl em sua última grande obra "A crise das ciências européias e a fenomenologia transcendental", onde são apresentadas criticamente noções fundamentais e preliminares ao entendimento da Ontopsicologia, tais como corpovivo (Leib), entropatia (Einfühlen), intersubjetividade, mundo-da-vida (Lebenswelt), epoché e redução fenomenológico-psicológica. Com os desdobramentos pós publicação da "Crise", foram analisadas finalmente as contribuições de filósofos e a influência da obra na psicologia e psiquiatria, culminando com os primeiros acenos da noção de "Ontopsicologia", a qual foi feita por autores da Psicologia existencial humanista, antes mesmo do trabalho clínico e das descobertas de Antonio Meneghetti, fundador da Ontopsicologia.
\end{abstract}

Palavras-chaves: Ontopsicologia; fenomenologia; epistemologia; psicologia existencial humanista, inovação em abordagens clínicas.

\section{Historial and Epistemological roots of Ontopsychology}

\begin{abstract}
This work analyses the ontopsychological methos historical and epistemological roots. It was elaborated by means of a bibliographic review where Edmund Husserl's works and those of his critics, but also post-husserlian thinkers stand out. In a first moment, it presents the relevance of such studies for the theory of knowledge and for the innovation of contemporary clinical approaches. In a second step, it analyses the historical-teleological path of Edmund Husserl in his last master piece "The crisis of european sciences and the transcendental phenomenology", where fundamental and preliminary notions for Ontopsychology are critically analysed, such as living body (Leib), entropathy (Einfühlen), intersubjectivity, lifeworld (Lebenswelt), epoché and phenomenological-psychological reduction. Unfolding Husserl's work in the "Crisis", it finally analyses the contributions of philosophers and the influence of his works in psychology and psychiatry, resulting in the first signs to the notion of "Ontopsychology" proposed by authors in the humanistic existencial psychology, before the clinical experimentation and discoveries made by Antonio Meneghetti, founder of Ontopsychology.
\end{abstract}

Key words: Ontopsychology, fenomenology, epistemology, humanistic existencial psychology, innovation in clinical approaches.

\section{Raízes Históricas y Epistemológicas de la Ontopsicología}

Resumen: Este artículo tiene por objetivo analizar los orígenes históricos y raíces epistemológicas del método ontopsicológico. Fue elaborado por medio de una revisión

\footnotetext{
${ }^{1}$ Doutor em Psicologia Clínica pela Pontifícia Universidade Católica de São Paulo PUC-SP, Doutorando em Engenharia Elétrica pela UNICAMP com pesquisa sobre a física dos Campos Semânticos; Mestre em em Filosofia pela PUC/SP, Docente, Formador e Empresário.
} 
bibliográfica con destaque para obras de Edmund Husserl y sus comentadores, así como de otros filósofos post-husserlianos. En un primer momento se presentó la relevancia del estudio del método ontopsicológico para la teoría del conocimiento y para la innovación de los métodos clínicos contemporáneos. A continuación, se analizó el recorrido históricoteleológico hecho por Edmund Husserl en su última gran obra "La crisis de las ciencias europeas y la fenomenología trascendental", donde se presentan críticamente nociones fundamentales y preliminares al entendimiento de la Ontopsicología, tales como cuerpo vivo (Leib), entropatia (Einfühlen), intersubjetividad, mundo de la vida (Lebenswelt), epoché y reducción fenomenológico-psicológica. Con los desdoblamientos después de la publicación de la "Crisis", se analizaron finalmente las contribuciones de filósofos y la influencia de la obra en la psicología y la psiquiatría, culminando con los primeros acentos de la noción de "Ontopsicología", la cual fue hecha por autores de la Psicología existencial humanista, antes incluso del trabajo clínico y de los descubrimientos de Antonio Meneghetti, fundador de la Ontopsicología.

Palabras claves: Ontopsicología; la fenomenología; epistemología; psicología existencial humanista, innovación en enfoques clínicos.

Pesquisa desenvolvida com apoio financeiro do Conselho Nacional de Desenvolvimento Científico e Tecnológico (CNPq).

\section{Introdução}

Dentre os problemas de pesquisa mais atuais e fundamentais no campo da Psicologia Clínica contemporânea está a investigação de critérios epistemológicos interdisciplinares que possam nortear o trabalho psicoterapêutico, em qualquer abordagem, uma vez que o psicólogo se encontra diante de situações cada vez mais complexas, envolvendo problemáticas existenciais com implicações éticas, econômicas, ambientais, de relação, mas não apenas.

Para a Ontopsicologia, a clínica contemporânea é um lugar muito peculiar, onde a vida pode escorrer de modo forte, aberto, sem todas as amarras, filtros e padrões aos quais estamos submetidos no cotidiano. A clínica é espelho da vida, onde podemos nos ver a olhos nus, explorar caminhos não vistos e fazer a verificação crítica do nosso Eu lógico histórico.

Nesse sentido, a Ontopsicologia tem uma dupla contribuição: representa uma reforma do método de investigação, com critérios epistemológicos norteadores da atividade do pesquisador em seu trabalho de busca de evidências clínicas, mas também dispõe de instrumentos de análise e intervenção aprimorados ao longo das últimas quatro décadas, que complementam e qualificam os conhecimentos e técnicas atualmente existentes.

Esse artigo é o primeiro de uma série e visa promover o diálogo com as mais diversas correntes científicas da Psicologia. Explicitará as origens históricas e epistemológicas da Ontopsicologia, suas ligações com o pensamento de Edmund Husserl e os desdobramentos práticos e teóricos de Antonio Meneghetti, por meio de uma revisão bibliográfica. 
Para a escola ontopsicológica, fundamental é a capacidade dos operadores de conhecimento de por em relevo a causa informante (ou informática ou informativa) da energia variável (MENEGHETTI, 2011), ou seja, aquela informação já ativa no "mundo-da-vida", mas que devido às constantes interferências cerebrais, que agem como heurísticas desviadoras na atividade racional humana (KAHNEMAN \& TVERSKY, 2002), não chega à consciência ou, quando chega, não é tipicamente preferida pelo sujeito. Em última instância, porém, as decisões determinam o curso histórico daquela individuação na globalidade existencial da qual é parte (AZEVEDO, 2017).

O método ontopsicológico é um processo racional de conhecimento. Em termos sintéticos, podemos dizer que as diversas interações com as quais entramos em contato produzem variações organísmicas, ou seja, variações em nosso corpo-vivo (Leib). Essas variações, por sua vez, dão início ao processo das imagens em seus diversos níveis: visivo, psicológico, intuitivo etc. Porém, ao conhecer e analisar, apesar de sofrer e produzir essas imagens, somos ignorantes diante delas e damos prioridade aos chamados sentidos superiores e a tudo o que acreditamos ser verdadeiro por cultura, educação etc., em detrimento do dado atual. Ao perder a atualidade intuitiva do nosso corpo-vivo, reduz-se o raio de qualquer pesquisa e de qualquer conhecimento, pois passamos a confiar mais em critérios heterosubjetivos, em métodos de conhecimento mediado do que no conhecimento imediato da intuição originária. Ou seja, conhecemos o Eu formado pela sociedade aplicado aos diversos objetos de estudo, e não aquilo que o Eu originário, o Eu da vida, impacta e informa.

A solução proposta pela Ontopsicologia é a psicoterapia de autenticação, que significa rever o Eu formado pela sociedade, revisitar, relativizar e superar estereótipos e complexos para recuperar a percepção organísmica e refletir a vida. Esse processo visa recuperar, ao menos em parte, esse quântico nativo de inteligência intuitiva para sermos mais racionais. $\mathrm{Na}$ medida em que se recupera esse critério, é consequencial a mudança do próprio estilo de vida, uma vez que temos elementos para escolher em conformidade com a nossa natureza. Esse critério constituinte do humano a escola ontopsicológica denominou Em Si ôntico.

O método ontopsicólogico se utiliza de seis instrumentos de análise com os quais é possível colher a intuição acerca da situação que se pretende analisar: 1) sintoma ou problema, 2) anamnese linguística e biográfica histórica, 3) fisionômico-cinésico-proxêmica, 4) sonhos, 5) campo semântico e 6) resultado. Destes critérios, são exclusivos da Ontopsicologia o campo semântico e o método para compreensão dos sonhos. 
Igualmente importante é a dimensão de inovação aportada pelo método ontopsicológico de análise e intervenção e, portanto, é preciso avaliar os resultados de sua aplicação: esse método pode auxiliar com efetividade na resolução de problemas e sintomas?

A Ontopsicologia nasce como proposta de resolução ao problema crítico do conhecimento, como proposta de revisão e ampliação do método científico fornecendo critérios epistêmicos para fundamentar a intuição do homem produtor de conhecimento. Ela propõe uma técnica para realizar a revisão crítica da consciência, sobretudo do cientista, mas também do psicólogo e de qualquer operador que se coloque a serviço da humanidade, de forma a recuperar a capacidade natural ao nexo ontológico. Ao final, todo o esforço da Ontopsicologia visa que a Ciência e a Filosofia sejam instrumentos seguros de serviço à evolução da vida neste planeta.

\section{Referencial Teórico}

\subsection{A “Crise das Ciências" e a Ontopsicologia}

A obra "A crise das ciências européias e a fenomenologia transcendental" é preliminar e fundamental para a compreensão da tarefa científica da Ontopsicologia por seu fundador, Antonio Meneghetti ${ }^{2}$, por causa da elaboração madura do conceito de "mundo-davida" (Lebenswelt) e pelas propostas feitas à Psicologia com as noções de Einfühlen (entropatia), Leib (corpo-vivo), intersubjetividade e, metodologicamente, pelo esclarecimento acerca da necessidade da redução fenomenológico-psicológica.

Já em 1911, Husserl ${ }^{3}$ chama a atenção para o fato que nas ciências físico-matemáticas, a maior parte do trabalho resulta de métodos indiretos. Por conta disso, somos muito propensos a superestimar tais métodos e a desconhecer o valor das apreensões diretas (...), da intuição direta (HUSSERL, 1991, p. 62). Husserl defende a ideia de que as ciências devam superar essencialmente dois preconceitos: 1) aquele com relação às ideias de outros pensadores - visto que, de fato, boa parte do trabalho realizado pelos cientistas resulta do usufruto de resultados atingidos por outros cientistas, e não de intuições diretas próprias - e 2) o preconceito dos fatos, para que não reste prisioneira de métodos indiretos de matematização

\footnotetext{
$21936-2013$

$31859-1938$
} 
e simbolização, cuja raiz histórica, para Husserl, é a física matemática de Galileu Galilei ${ }^{4}$ (HUSSERL, 1991). Verificar-se-ia um grande progresso nas ciências, caso se reconhecesse e recuperasse o enorme valor da intuição direta, que é, para ele, sinônimo de apreensão fenomenológica da essência. Há aqui um campo infinito de pesquisa por realizar, uma ciência de novo tipo, a qual, embora não faça uso dos métodos indiretos de matematização e simbolização, pode obter conhecimentos autenticamente rigorosos (HUSSERL, 1991).

Para Husserl, a função da filosofia é dar rigor à evidência, sendo ela o fundamento para depois poder fazer ciência: matemática, lógica, física, psicologia etc. A carência de um método verdadeiramente intuitivo - que atinja metodicamente a evidência originária - e, por outro lado, a hiper-presença de métodos indiretos - matematização e simbolização - provocou uma espécie de "atrofia" da ciência, que tornou-se prisioneira do preconceito dos fatos. Em síntese: as ciências objetivas não são capazes de tematizar o ser da natureza. Para Husserl, o saber em torno à natureza, que é próprio das ciências naturais, não equivale a um conhecimento verdadeiramente definitivo, a uma explicação da natureza (HUSSERL, 1976, p. 193). A possibilidade de deduzir, induzir e prever requer uma ulterior explicação e fundamentação.

Partindo dessa perspectiva, Husserl considera que as teorias são pouco mais do que máquinas computacionais acompanhadas de um mínimo de insight racional que os gregos honraram com o nome de "teoria". A racionalidade técnica das ciências relativa e unilateral que deixa o outro lado [a intuição] na completa irracionalidade (HUSSERL, 1974, p. 15).

A reação natural às afirmações de Husserl não poderia ter sido outra que surpresa e indignação, visto que as ciências obtinham notoriamente contínuos sucessos. Husserl não pretendia, de fato, desvalorizar a grandeza dos gênios criativos que operaram no âmbito na atitude natural, nem tampouco desmerecer a própria atitude natural, na qual operam as ciências naturais. Seu intuito era indicar que para a sua completude, o método das ciências deve recuperar a intuição direta, pois a sua exclusão impede às ciências de atingir uma verdadeira compreensão e explicação de seus objetos. Elaboram-se leis sem compreender a sua motivação:

Deduzir não equivale a explicar. Prever, ou ainda, reconhecer e depois prever as formas objetivas da estrutura e dos corpos químicos ou físicos - tudo isso não esclarece nada, antes, tem necessidade de um esclarecimento. (HUSSERL, 1976, p.193)

\footnotetext{
${ }^{4} 1564-1642$
} 
Acusa-se a dificuldade da pesquisa, a insuficiência e a imprecisão dos instrumentos de medida, mas os problemas de uma autêntica humanidade, os assim chamados problemas da razão, restam ainda hoje à margem da ciência. De todo modo, ela deveria ser capaz de compreender a vida, o mundo e o homem, assim como propunha a célebre proposição 6.52 do Tractatus Logico-Philosophicus de Wittgenstein: "Sentimos que, ainda que todas as possíveis questões da ciência recebam resposta, os problemas da nossa vida não foram nem mesmo tocados" (WITTGENSTEIN, 1921).

Para que as ciências atinjam o seu pleno esclarecimento, faz-se necessária uma crítica da ciência. Todas as ciências estão em última instância fundadas na evidência e isso, pode-se dizer, é um dado comumente aceitável. Podemos afirmar ainda que a evidência e a experiência sempre envolvem um sujeito, e isso quer dizer, fenomenologicamente, que todas as ciências se fundam na intencionalidade produtiva da subjetividade. As consequências desse fato é que não são fáceis de enfrentar, pois levam à conclusão que para sermos radicalmente objetivos temos que tornar a investigação radicalmente subjetiva (KOCKELMANS, 1970).

O fundamento do conhecimento, para Husserl, está na intuição imediata. Ao invés de apoiar-se na dedução a partir do ego, como Descartes, ele propõe-se a realizar uma descrição da vida do ego em sua correlação intuitiva com o campo das objetividades sensíveis e categoriais eidéticas ${ }^{5}$, as quais constituem os conceitos elementares e os pressupostos de todas as ciências. Trata-se de retornar à evidência originária e não às falsas evidências do naturalismo. Isso significa que o paradigma da razão husserliana é a evidência imediata e não as conclusões do método indutivo-dedutivo. Por meio da intuição das essências, a fenomenologia provê um fundamento radical às ciências (KOCKELMANS, 1970).

A crítica mais radical de Husserl dirige-se aos filósofos, aos quais, na qualidade de "funcionários da humanidade", caberia a tarefa de restabelecer o nexo entre ciência e "mundo-da-vida" e, secundariamente, aos homens de ciência, por sua responsabilidade na construção concreta de uma ciência em favor do humano autêntico.

A resolução deste enigma deveria passar pela resolução do conflito entre as duas posições principais da filosofia moderna: objetivismo fisicalista e subjetivismo transcendental. Não é possível resolver este conflito apelando para modelos de subjetividade postulados (Kant), nem tampouco para a "necessidade" não demonstrada de um objeto transcendente (Descartes). Seria necessário superar pré-juízos históricos milenares e

\footnotetext{
${ }^{5}$ A experiência fenomenológica não se restringe às objetividades sensíveis, mas inclui dados não sensíveis, chamados "categoriais". As essências são atingidas pela redução eidética ou "redução à ideia", de onde "categoriais eidéticas".
} 
empreender a análise fenomenológica da intencionalidade, retirando do anonimato o "mundoda-vida", fundamento último das operações e elaborações de todas as ciências.

A origem desse contraste está no nascimento das ciências naturais modernas, cujo caráter distintivo é a sua transformação por Galileu em ciências naturais matemáticas, ao ponto de influenciar a própria concepção de filosofia. O "equívoco" estaria na não compreensão do problema da simbolização, ou seja, um hábito simbólico que visa representar o "mundo-da-vida", tomando por verdadeiro ser o que, de fato, é apenas um método para realizar previsões científicas em um progressus in infinitum. A partir daí, as ciências passaram ao estágio "técnico", alienando-se dos problemas tipicamente humanos e perdendo a compreensão da origem de suas próprias operações. O verdadeiro mal-estar faz-se sentir de maneira mais evidente na Psicologia, onde as dificuldades da aplicabilidade de um naturalismo eram evidentes.

O elo seguinte na corrente histórico-teleológica traçada na "Crise" é Descartes. É surpreendente a ligação entre a matematização galileana - onde o psíquico existe apenas como resíduo - e o dualismo cartesiano. Descartes encontra um mundo já transformado por Galileu, é herdeiro de um mundo privado do "meramente subjetivo" e acredita em um método que possa ser aplicado, indistintamente, também na esfera subjetiva, favorecendo uma falsa interpretação da subjetividade. Descartes, ao mesmo tempo, fundador da ideia moderna de um racionalismo objetivista e inaugurador da pesquisa transcendental, parecia inicialmente ser o filósofo que tinha condições de por em relevo o "mundo-da-vida", por meio de sua epoché radical, mas trai a si mesmo, restando prisioneiro das evidências galileanas.

Berkeley $^{6}$ e Hume $^{7}$ voltam-se, por sua vez, contra os próprios modelos da racionalidade, reduzindo conceitos fundamentais a meras funções psicológicas. A autêntica motivação filosófica contida no ceticismo humiano é a negação do objetivismo, pois a "alma" de Hume, com suas impressões, ideias e leis associativas "produz" o mundo. Hume demonstra com seu ceticismo a inutilidade de tentar fundar qualquer objetivismo, mas, ao mesmo tempo, inicia uma espécie de subjetivismo radical, que torna subjetivo o próprio mundo. Por essa razão, na ótica teleológica da história da filosofia traçada por Husserl, também Hume desperdiça uma grande oportunidade, aquela de refutar definitivamente o psicologismo investigando a constituição subjetiva do fenômeno "mundo".

\footnotetext{
6 1685-1753.

$71711-1776$.
} 
O último filósofo na corrente histórico-teleológica de Husserl é $\mathrm{Kant}^{8}$, cujo mérito é ter conduzido, pela primeira vez na história da filosofia, e de modo consequente, uma investigação do terreno da subjetividade transcendental como "fundadora" da objetividade. Mas Kant é herdeiro de Newton, assume como válida a noção de mundo das ciências físicomatemáticas e, adicionalmente, não dispunha de um método de investigação da subjetividade autenticamente intuitivo, deixando o fenômeno transcendental "mundo" ainda oculto.

Husserl, portanto, caracteriza o problema de Hume como "o mais transcendental de todos", porque Hume acusa com maior consciência com seu empirismo cético o problema de um mundo que é mundo por meio de uma operação realizada pela subjetividade. Descartes chega ao portão de ingresso do "reino de evidências originárias", que Husserl denomina "mundo-da-vida" (HUSSERL, 1976, p. 130), mas se paralisa pela necessidade de demonstrar que havia descoberto a alma (HUSSERL, 1976, $\S 17$ e 18). Seria preciso seguir adiante e descrever como o mundo, que consideramos uma obviedade, de fato se constitua na esfera da subjetividade.

Husserl não se propõe a descrever esta subjetividade pura ${ }^{9}$ - Ur-ich (ou pólo egológico) - mas descreve suas vivências, chegando também a afirmar que o objeto de estudo da psicologia deveria ser este "eu originário" (Ur-ich), como ele constitui o mundo, por meio de que operações e como se dá a sua relação com os outros pólos egológicos, ou seja, como seja possível a intersubjetividade (ZILLES, 1996).

Outro aspecto fundamental da "Crise" é enfrentar o que Husserl denomina de "paradoxo da subjetividade", contemporaneamente objeto no mundo e sujeito para o mundo (HUSSERL, 1976, § 53). Para tanto, a "Crise" apresenta duas vias de acesso à filosofia transcendental fenomenológica: 1) a partir da reconsideração do "mundo-da-vida" já dado, ou seja, "uma mutação total da atitude no interior da epoché, acerca da ideia diretiva de um conhecimento objetivo do mundo" (HUSSERL, 1976, p.139), e 2) a partir da psicologia (HUSSERL, 1976, $\S 28$ a 73), uma psicologia porém distinta daquela de $\mathrm{Wundt}^{10}$, Brentano $^{11}$ ou de Freud ${ }^{12}$.

\footnotetext{
${ }^{8} 1724-1804$.

9 "No que tange ao ego, damo-nos conta de nos encontrarmos em uma esfera de evidência; a tentativa de indagar para além dela, seria um não-senso". (Hu VI, p. 192)

${ }_{10}^{10} 1832-1920$.

${ }^{11} 1838-1917$.

12 1856-1939.
} 
O significado da "mutação total da atitude" inerente à epoché transcendental é descrito por Husserl no Anexo $\mathrm{XX}^{13}$, o qual é fundamental para a Ontopsicologia. A sua essência é a abstenção da participação na produção das validades do mundo já dado. Só mediante essa abstenção atingimos esse novo "modo de tematizar o mundo", o qual Husserl denomina "serjá-dado do mundo como tal" e, portanto, "podemos penetrar no que o mundo é enquanto terreno de validade da vida natural (...) e, correlativamente, no que a vida natural e a sua subjetividade em definitiva são, a subjetividade enquanto pura subjetividade que atua na produção das validades." (HUSSERL, 1976, p. 151):

Com essa peculiar epoché, estamos agora em condições de investigar a vida universal subjetiva e intersubjetiva. É justamente essa epoché a via para "atingir as máximas profundidades filosóficas" e, até mesmo, "uma mutação radical de toda a humanidade". (HUSSERL, 1976, p. 154).

Talvez resulte até mesmo que a atitude fenomenológica total e a epoché que lhe é inerente são destinados a produzir essencialmente, antes de tudo, uma completa transformação pessoal, que inicialmente poderia ser comparada a uma conversão religiosa, mas que, para além disso, é a maior evolução existencial que esteja conexa à humanidade como tal. (HUSSERL, 1976, p. 140)

Husserl quer explicitar, por meio do produzir-se do "mundo-da-vida", a operação do ego transcendental. Tal demonstração deveria ter sido feita pela psicologia, mas esta não foi capaz de fazê-lo por conta do modo como foi concebida. Tal operação é exatamente aquilo que Husserl distingue como sendo própriamente a "vida" do ego transcendental.

\begin{abstract}
A atuação da inversão total consiste nisto: a infinidade da experiência real ou possível do mundo se transforma na infinidade de uma experiência "transcendental" real ou possível, na qual é experimentado, antes de tudo, o mundo e a sua experiência natural enquanto "fenômeno". (...) graças à redução transcendental nos encontramos no portão de ingresso do reino jamais explorado da "mãe do conhecimento". (HUSSERL, 1976, p. 156)
\end{abstract}

Acerca do "mundo-da-vida", Carr (1987) destaca três elementos-chave: o seu caráter de ser "já-dado" (Vorgegebenheit), que significa ser já dado antes de qualquer ciência ou substrução lógico-teórica; o fato que o "mundo-da-vida" é descrito como público, ou seja, constituído intersubjetivamente; e, por fim, o fato que Husserl também lhe atribui "objetos culturais", dentre os quais a própria ciência, enquanto produção cultural humana. É justamente a riqueza e a radicalização do caráter intersubjetivo do "mundo-da-vida" que Dan

${ }^{13}$ O Anexo XX, intitulado "Atitude natural e epoché. Realização da validade do mundo; qual realização é inibida pela epoché", é fundamental para a Ontopsicologia porque nele é possível antever diversos aspectos que foram ulteriormente explicitados a partir da descoberta do campo semântico, mas também do Em Si ôntico. 
Zahavi ${ }^{14}$ destaca (ZAHAVI, 2003). Aceitando a constituição intersubjetiva da realidade, devese levar a sério não só o consenso, mas também a discordância dos sujeitos que experimentam o mundo. Outra perspectiva é aquela que considera o "mundo-da-vida" como um universum de ser e de verdade (MARBACH et. al., 1996). O conceito de vida pareceria aqui apontar na mesma direção da assim chamada Lebensphilosophie - Henri Bergson, Wilhelm Dilthey -, constituindo uma oposição ao pensamento conceitual intelectual.

O "mundo-da-vida" é o mundo da experiência inteligível, relativo à subjetividade em ato de experiência (HUSSERL, 1976, p. 127), mas também da vida quotidiana, em nossa comunidade humana, enquanto uma comunidade de pessoas de normal sensibilidade e onde se dão normais trocas de comunicação (Marbach et. al., 1996). O contraste entre a subjetividade do "mundo-da-vida" e a objetividade do mundo científico jaz no fato que:

(...) este último [o mundo científico] é uma substrução teórico-lógica, que por
princípio não é perceptível, por princípio não é experimentável no seu ser próprio,
enquanto o elemento subjetivo do "mundo-da-vida" distingue-se onde quer que seja
e em qualquer coisa justamente pela sua experimentabilidade. O "mundo-da-vida" é
um reino de evidências originárias. (HUSSERL, 1976, p.130)

Portanto, o "mundo-da-vida" não é apenas um terreno que serve de fundamento para o mundo cientificamente verdadeiro, mas torna-se o tema para a fundação de uma nova "forma de ciência", uma nova forma de "fazer ciência" (MARBACH, et. al., 1996, p. 206).

O "mundo-da-vida" é um reino de fenômenos subjetivos que restaram anônimos. Tal reino jamais fora objeto de nenhuma ciência e cabe à filosofia tirar esse reino do anonimato e, com isso, também dar um fundamento último a si mesma e às ciências. Eis, portanto, o verdadeiro objeto da filosofia transcendental: “(...) todas as ciências se baseiam em um único fundamento, um fundamento que deve ser indagado cientificamente antes de todos os outros e este fundamento, adiciono, pode ser outro que a subjetividade anônima? "(HUSSERL, 1976, p.115)

Uma última consideração refere-se à importante distinção feita por Husserl entre "vida profunda" e "vida em superfície", tratada no $\S 32$, um dos mais importantes de toda a Parte III justamente porque o termo "vida" aparece centrado e definido neste parágrafo. Husserl utiliza-se de uma imagem proposta por Helmholtz ${ }^{15}$ acerca da natureza das superfícies, as

\footnotetext{
14 Filósofo dinamarquês, nascido em 1967, autor de "Husserl's Phenomenology. Cultural Memory in the Present", de 2003. Dirige o "National Research Council's Center for Subjectivity Research", na Universidade de Copenhagen, sendo também co-editor do "Journal of Phenomenology and the Cognitive Sciences".

15 Hermann Ludwig Ferdinand von Helmholtz (1821-1894). Médico e físico alemão, considerado um dos homens mais relevantes para a ciência no século XIX. Discípulo de Wundt, sofreu forte influência da filosofia de
} 
quais não têm qualquer suspeita da profundidade, da qual, todavia, as superfícies são uma mera projeção. Tudo o que pode se tornar consciente, como um campo de objetos mundanos “externos”, como escopos que a estes objetos se referem (...) na autorreflexão - tudo isso resta no âmbito da "superfície", a qual, mesmo que não seja advertida, é superfície de uma "dimensão profunda", infinitamente mais rica, o que para Husserl, vale tanto na vida meramente prática, em sentido quotidiano, quanto na vida teórica, de uma experiência científica ou de uma elaboração de pensamentos filosóficos. (HUSSERL, 1976, pp. 121-122)

Desse modo, Husserl justifica a autonomia deste problema, concluindo, com Helmholtz, que se revela a partir de então, uma "terceira dimensão", a qual absorve o tema "ciência objetiva", assim como todos os demais temas que se encontram na "superfície". Para compreender o que Husserl quer dizer com "absorve o tema ciência objetiva", basta dizer que impomos um conceito de objetividade estranho à vida profunda, adotamos uma objetividade mediada, abandonando aquela imediata do "mundo-da-vida".

Trata-se de uma passagem fundamental, pois permite compreender que a "vida em superfície" é marcada pela constante participação na produção das validades do mundo já dado. A "vida profunda" requer a abstenção dessa participação, ou seja, só é possível investigar os modos de produção de validade do mundo abstendo-se de participar de sua produção. É na inversão do sentido usual que damos à noção de "vida" que as contribuições da "Crise" podem ser compreendidas: "Esta total abstenção, a qual inibe completamente este modo de vida que até então fluía ininterruptamente, significa uma completa inversão da vida como um todo, um modo de vida completamente novo.” (HUSSERL, 1976, p. 153)

\footnotetext{
Ela [a epoché transcendental] produz uma atitude que está acima do ser-já-dado das validades do mundo; (...) Em outras palavras, nós assumimos uma atitude que se põe acima da vida universal (subjetiva e intersubjetiva) da consciência na qual o mundo, para aqueles que o vivem ingenuamente, é "aqui", indiscutivelmente à mão, o campo de todos os interesses da vida já praticados e que continuamente se reproduzem. (HUSSERL, 1976, p. 153)
}

Mas a ciência sempre menosprezou o que é meramente subjetivo-relativo, quando na verdade, ele é a última fonte possível de evidência e verificação: “O mundo-da-vida é por princípio um universo intuível - o mundo objetivamente verdadeiro é uma substrução lógica que por princípio não é intuível” (HUSSERL, 1976, p. 130). O elemento subjetivo do "mundo-da-vida" é caracterizado justamente pelo fato de seu caráter de constantemente já

Fichte, de quem foi amigo pessoal, e de Kant, dedicando-se, entre outras pesquisas, à busca de provas empíricas [a partir da fisiologia] para as teorias filosóficas de Kant. 
dado, de constantemente experimentável e, justamente por ser ele mesmo experimentado em sua presença imediata, ou ele mesmo em outros modos de datitude ${ }^{16}$, é que Husserl o define como "um reino de evidências originárias". (HUSSERL, 1976, p. 130)

O que Husserl quer demonstrar é o fato que a experiência é uma pura evidência que se apresenta no "mundo-da-vida", é a fonte de evidência das constatações objetivas das ciências, as quais, por sua vez, nunca são experiências da objetividade (HUSSERL, 1976, p. 131). O problema, portanto, é como esclarecer o nexo das ciências com o "mundo-da-vida" por meio de uma cientificidade nova, que não é de tipo matemático, ou lógico em sentido tradicional.

Desse modo, Husserl explicita como um problema aparentemente "parcial" se torna um "problema filosófico" total e, portanto, prioritário, tendo suas conseqüências em uma mutação da teoria do conhecimento, na teoria da ciência, na ciência - que perde sua autonomia, bem como toda a esfera lógica, enquanto não se fundarem no "mundo-da-vida".

Quanto à psicologia, Husserl dedica a ela a última parte da "Crise", que trata da "via" da psicologia. Husserl afirma que devemos enfrentar preconceitos milenares que determinam o nosso modo de compreender os fenômenos psíquicos mais simples, como os da percepção sensível, tarefa que é feita à luz da distinção fundamental entre "Körper" (corpo) e "Leib" (corpo próprio ou corpo vivo). Como se dá, por exemplo, a nossa percepção?

(...) participa evidentemente e imancavelmente o nosso corpo próprio (Leib), que jamais nos falta em nosso campo perceptivo, com os inerentes "órgãos perceptivos" (olhos, mãos, orelhas etc.). Eles desenvolvem um papel constante para a consciência, enquanto atuam no ver, no sentir etc., unidamente à inerente mobilidade egológica, à assim chamada cinestesia. Todas as cinestesias, qualquer "eu movo", "eu faço", são conexas entre si na unidade universal, por isso a inatividade cinestética é um modo do "eu faço". (HUSSERL, 1976, p. 108)

Mas qual a diferença entre corpo e corpo próprio (corpo vivo)?

(...) o corpo (Körper) e o corpo próprio (Leib) são essencialmente diversos; o corpo próprio é o único corpo perceptivo, é o meu corpo. Como surja uma consciência pela qual o meu corpo próprio assume a validade de ser de um corpo entre os outros corpos, e como, por outro lado, certos corpos do meu campo perceptivo cheguem a valer como corpos próprios, corpos próprios de outros eu-sujeitos "alheios": são, estas, perguntas necessárias. (HUSSERL, 1976, p. 109)

Somos concretamente corpóreos, mas não apenas corpóreos. O nosso corpo "é" no mundo segundo uma intencionalidade que o constitui continuamente. Somos um corpo animado quando temos consciência do mundo e participamos ativamente do mundo, mas

\footnotetext{
${ }^{16}$ Latim dato + sufixo "ità" a indicar "a qualidade do que é simplesmente dado".
} 
quando nos voltamos para o mundo interior, quando nos apercebemos transcendentalmente, "temos um corpo" e "temos o mundo":

\begin{abstract}
Nós que vivemos na consciência acordada, somos constantemente ativos sob o fundo de um passivo ter-o-mundo (Welthabe); sob este fundo nós sofremos afecções por parte dos objetos que são já dados no campo consciencial, deles nos ocupamos em muitos modos; em nossos atos os objetos tornam-se objetos "temáticos". A título de exemplo, cito a explicitação da observação das propriedades do que aparece perceptivamente; ou ainda, cada ato voltado a extrair conclusões, a estabelecer relações e a exercer identificações e distinções; ou ainda, também o nosso ativo avaliar, o nosso esboçar propósitos, o nosso ativo realizar escopos prefixados. (HUSSERL, 1976, p. 110).
\end{abstract}

Dentre os fatores segundo os quais, para Husserl, a filosofia não atingiu o seu télos ocupa um papel central aquilo que ele denominou de fatal separação da filosofia transcendental da psicologia. Isso porque a filosofia transcendental carregava consigo a peculiar necessidade de superar a diferença entre subjetividade empírica e a subjetividade transcendental, ou nos termos de Husserl: "Eu, enquanto eu transcendental, constituo o mundo e, por outro lado, enquanto alma, sou um eu no mundo". (HUSSERL, 1976, p. 205)

A consciência da intersubjetividade deve tornar-se um problema transcendental e a psicologia não deveria ficar indiferente diante desse problema. Para Husserl, de fato, "só depois da elaboração de uma genuína psicologia se poderia chegar a um conceito científico da razão e de suas operações" (HUSSERL, 1976, p. 206). Ocorre que a filosofia afasta-se da psicologia tomando precauções diante do psicologismo. Isso se deve ao fato que a psicologia adotou - por causa das imposições feitas pela própria idéia moderna de uma ciência universal objetiva construída em base ao dualismo psico-físico - um modelo naturalista. É esse também o motivo que impediu, para Husserl, que a psicologia pudesse assumir a sua tarefa.

\footnotetext{
Se a psicologia não tivesse fracassado, teria realizado um necessário trabalho de mediação a favor de uma filosofia transcendental realmente concreta e livre de qualquer paradoxo. Ao invés disso, a psicologia falhou, porque desde quando foi fundada como psicologia autônoma com relação às ciências da natureza, descuidouse de investigar o sentido da tarefa que por essência lhe era imposta enquanto ciência universal do ser psíquico. (HUSSERL, 1976, pp. 206-207).
}

A psicologia se pôs tarefas e elaborou seu método segundo o modelo das ciências naturais e, por isso, a sua história foi marcada por uma série de crises. Se a psicologia tivesse atuado a tarefa de ser a ciência universal do ser psíquico, teria sido levada a ser a ciência da subjetividade transcendental e, por isso, transformar-se-ia em filosofia transcendental. Para Husserl, portanto, há um incindível parentesco entre psicologia e filosofia transcendental. 
Torna-se evidente que o homem, embora viva no mundo, é cego diante da enorme dimensão dos problemas transcendentais. Tal dimensão permanece-lhe em um anonimato fechado:

\begin{abstract}
Sou realmente um ego transcendental, mas não sou consciente disso; sou imerso em uma atitude particular, aquela natural, dirijo-me exclusivamente aos pólos objetuais, completamente ligado aos interesses e tarefas que eles determinam. (...) [Por conseqüência], as minhas auto-percepções são produzidas por minhas operações, na unidade da minha auto-objetivação (...), tornando-se produtos habituais. Esta operação completa, cujo pólo egológico último sou eu mesmo enquanto ego, pode ser interrogada transcendentalmente e explicitada em sua estrutura de validade e sentido. (HUSSERL, 1976, pp. 209-210).
\end{abstract}

Ao contrário, constata-se que o psicólogo propõe a tarefa de reconhecer-se como eu mundano, objetivado, mundanizado, ou seja, quer conhecer concretamente a alma, nos moldes de um conhecimento objetivo, como homem entre as coisas, entre outros homens, animais etc. Com isso, Husserl explicita como a via que leva a uma filosofia transcendental deva passar por uma psicologia concretamente atuada. Mas como seria possível para Husserl chegar metodicamente a tal psicologia?

Após analisar as tentativas de atuar uma psicologia nos moldes das ciências naturais pelas principais correntes da psicologia científica de seu tempo ${ }^{17}$, Husserl apresenta sua proposta para o método psicológico, denominado de "redução fenomenológico-psicológica", cujo cerne é a atitude do "expectador desinteressado".

\begin{abstract}
Para chegar a uma psicologia pura, o psicólogo não pode assumir as diversas validades da pessoa que constitui o seu tema, durante a sua investigação ele não deve tomar qualquer posição em relação a elas; deve evitar fazê-lo universal e preliminarmente, com respeito a todas as intencionalidades ainda ignoradas e ainda ocultas nas profundezas da sua vida, independentemente do fato que para a pessoa em questão sejam conscientes ou inconscientes em um sentido particular. Isso investe todos os hábitos, todos os interesses, sejam aqueles temporários, sejam aqueles que persistem ao longo de toda a vida. (HUSSERL, 1976, pp. 240-241).
\end{abstract}

Assim como no caso da epoché transcendental, caso se participe como cointeressados, cai-se fora do próprio tema proposto. O que é aqui particularmente importante é o fato que seja possível tematizar os sujeitos em uma dupla atitude onde temos, "de um lado, um referir-se puramente interno das pessoas àquelas coisas das quais são conscientes (...); de outro, o real ser-em-relação das pessoas, enquanto realidade no mundo real, com as coisas deste mesmo mundo". Só assim, por meio da epoché universal da validade, a psicologia atinge, para Husserl, o seu tema. Suspendendo as suas validades, ela colhe antes de tudo a "esfera interior" dos homens. Também a epoché do psicólogo deve ocorrer "de uma só vez",

\footnotetext{
${ }^{17} \mathrm{Cfr} . \S \S 60-68, \mathrm{Hu}$ VI.
} 
neutralizando a totalidade da participação nas validades que as pessoas temáticas, e todas as pessoas em geral, realizam implícita ou explicitamente. Mais ainda:

A sua epoché investe todas as almas, portanto, também aquela do próprio psicólogo: isso implica uma abstenção da participação naquelas validades que todas as pessoas atuam em sua relação com a realidade do mundo objetivo, nos modos da vida quotidiana natural - e esta abstenção ele deve atuar justo enquanto psicólogo. (HUSSERL, 1976, p. 242).

Nesta atitude, o psicólogo produz em si mesmo o que Husserl denomina "expectador desinteressado", um investigador de si mesmo e dos outros, enquanto exerce o seu trabalho de psicólogo. Poderia surgir aqui então a pergunta: mas como, por meio desta atitude, um outro sujeito poderia tornar-se tema de uma investigação?

Para Husserl, apenas na atitude fenomenológico-psicológica atinge-se como tema o mundo "interior" do sujeito, que é um mundo essencialmente unitário e, em função da constituição intersubjetiva do mundo, a totalidade universal da vida intencional:

[Ele, o psicólogo, atinge] a sua própria vida na originalidade originária, mas também a vida daqueles que vivem acomunados com ele; e cada vida, com a sua intencionalidade, penetra intencionalmente na vida dos outros, e todos, de modos diversos, próximos ou remotos, são entrelaçados na comunidade da vida. Para o psicólogo que vive esta vida, mas na atitude do "observador desinteressado", é acessível tematicamente qualquer vida intencional, assim como é vivida por qualquer sujeito e por qualquer comunidade particular de sujeitos, as atuações, o agir perceptivo ou de todo modo experimental, as mutáveis opiniões em torno ao ser, à vontade etc. Por isso, o seu tema mais próximo e fundamental é a pura vida pessoal dos atos e, portanto, antes de tudo, a vida de consciência em sentido estrito, por assim dizer, é o aspecto superficial deste mundo espiritual, aquele que antes de tudo se revela; apenas aos poucos, abrem-se para ele as profundezas intencionais. (HUSSERL, 1976, p. 243).

No terreno do "mundo-da-vida", as almas não estão em relação de exterioridade, mas são internas umas às outras, unidas por meio da inerência intencional de suas comunidades de vida. Cada alma, reduzida à sua pura interioridade, tem um seu ser-por-si e um seu ser-em-si, tem a sua vida originalmente própria. Elas têm consciência do mundo porque têm experiências entropáticas ${ }^{18}$. Isso significa que na intencionalidade vivente-fluente que constitui a vida de um sujeito egológico são já preliminarmente implicados, intencionalmente, todos os outros egos no modo da entropatia (Einfühlung) e do horizonte de entropatia:

\footnotetext{
${ }^{18}$ Husserl cunha o termo alemão Einfühlung, o qual foi traduzido na tradição filosófica por "entropatia" ou "endopatia", para indicar a capacidade de empatia "íntimo a íntimo", a capacidade de sentir e refletir o mundo interior do outro com o meu corpo próprio (Leib). Trata-se de conhecer o outro de modo radical por meio da variação que ele origina na esfera do próprio (Eigensphäre).
} 
Uma epoché universal que compreenda realmente a si mesma revela que para as almas, em sua essência própria, não existe uma real separação, uma relação de exterioridade. Aquilo que é uma relação de exterioridade para a atitude naturalmundana da vida no mundo anterior à epoché (...), transforma-se em uma inerência pura intencional. Assim, o mundo que simplesmente é, e portanto também a natureza, transforma-se no fenômeno "mundo" a todos comum, "mundo para todos os sujeitos reais e possíveis"; nenhum sujeito pode subtrair-se à implicação intencional pela qual entra no horizonte de todos os sujeitos. (HUSSERL, 1976, p. 259).

Apenas uma psicologia deste gênero poderia atuar o sentido científico que lhe é peculiar e, evidentemente, a Psicologia não atingiria este intento abstraindo da corporeidade, como fazem as ciências naturais, que abstraem do que é espiritual, uma via que o próprio Husserl adverte conter excepcionais dificuldades:

(...) a epoché é o meio para tornar experimentável e para tematizar em sua pureza essencial os sujeitos, os quais, na via natural no mundo, experimentam a si mesmos e são experimentados em suas relações intencionais-reais com os objetos mundados. Assim eles se tornam, para um observador psicológico absolutamente desinteressado, "fenômenos" em um sentido novo e peculiar - e esta virada chamase justamente redução fenomenológico-psicológica. (HUSSERL, 1976, p. 247).

A atuação desta epoché torna acessível a esfera psíquica, leva à luz o seu ser e tudo o que "está" nela, penetrando, a partir das intencionalidades externalizadas, até aquelas internas, aquelas intencionalmente constitutivas. Porém, a epoché é para ele apenas o início necessário a uma experiência puramente psíquica. Husserl conclui sua incursão afirmando que, até então, a psicologia jamais tinha se movido nesse terreno e, ao mesmo tempo, preanunciando a tarefa da qual outros pesquisadores deverão incumbir-se no futuro:

\footnotetext{
Apenas quando houver uma similar psicologia, será possível avaliar os fatos multiformes e certamente preciosos fornecidos pela psicofísica e pela psicologia que a eles se remete, avaliá-los em seu verdadeiro conteúdo psicológico, e esclarecer quais sejam, de ambos os lados, os membros da relação das regulamentações empíricas. (HUSSERL, 1976, p. 253)
}

Não obstante todas as suas análises, porém, Husserl está ciente que, em sua vazia generalidade, a epoché nada esclarece, posto que é "apenas o portão de entrada, além do qual abre-se o reino da pura subjetividade. A verdadeira descoberta é a tarefa de um trabalho concreto, um trabalho muito difícil e muito diferenciado" (HUSSERL, 1976, p. 260), e é precisamente este o ponto de partida de Antonio Meneghetti com a Ontopsicologia.

\subsection{Da fenomenologia à Ontopsicologia}


A influência de Husserl no pensamento do século XX é enorme, estabelecendo diálogos com pensadores como Heiddeger ${ }^{19}$, Sartre $^{20}$, Merleau-Ponty ${ }^{21}$, Camus ${ }^{22}$, Carnap ${ }^{23}$, Gödel $^{24}$, Koiré ${ }^{25}$, Hermann Weyl ${ }^{26}$, Derrida ${ }^{27}$, Meneghetti ${ }^{28}$, entre outros.

Do ponto de vista histórico, interessa-nos destacar que alguns de seus discípulos desenvolveram suas idéias, enquanto outros tomaram rumos distintos, como Martin Heidegger, sem dúvida considerado o mais influente entre os discípulos de Husserl que, com a sua Existenzphilosophie, distancia-se do pai da fenomenologia e propõe uma ontologia dos modos de ser-no-mundo (ser-aí ou Dasein). Tal ontologia era um projeto já previsto por Husserl, conforme afirma em suas "Meditações Cartesianas":

A fenomenologia transcendental, sistemática e plenamente desenvolvida, é eo ipso uma autêntica ontologia universal. Não uma ontologia formal e vazia, mas uma ontologia que inclui todas as possibilidades regionais de existência, segundo todas as correlações que elas implicam. (HUSSERL, 1991, p. 132, grifo nosso).

As investigações filosóficas de Heidegger diferem daquelas de Husserl em ao menos três importantes aspectos: quanto à direção da investigação, quanto à temática e quanto ao método empregado. Quanto à direção, Heidegger, abandona a proposta husserliana de atingir algo como um ser-em-si ${ }^{29}$, o Ur-Ich, e desenvolve uma ontologia regional que analisa o Dasein, o modo típico da presença humana no mundo, cuja essência é justamente aquela de não ter uma essência. Heidegger investiga, portanto, o "ser-aí" do homem, o seu modo de abertura. Com relação à temática da investigação, ou seja, a atitude fenomenológica adotada, Heidegger não parte da esfera constitutiva, ou transcendental, mas sim daquilo que é a medianidade da existência e, desse modo, em alguma medida, na atitude natural. Se Husserl demonstra a possibilidade de adoção de diversas atitudes no interior do mundo-da-vida, ou seja, diversos "mundos" podem ser edificados sobre o "mundo-da-vida", com Ser e Tempo vemos um abandono dessa via. As disposições ontológicas do Dasein, por exemplo, não

\footnotetext{
19 1889-1976

$201905-1980$.

21 1908-1961.

22 1913-1960.

$231891-1970$

24 1906-1978.

${ }^{25} 1892-1964$

${ }^{26} 1885-1955$

27 1930-2004.

28 1936-2013.

${ }^{29}$ Cfr. $§ 2.7$ A “via” da Psicologia: "Cada alma, reduzida à sua pura interioridade, tem um seu ser-por-si e um seu ser-em-si, tem a sua vida originalmente própria."

${ }^{30}$ Publicada em 1927.
} 
podem ser entendidas como uma descrição das fenomenologias do Ur-Ich, e embora rigorosamente não se reduzam à uma mera atitude personalista, não são demonstráveis, o que poderia dar lugar à crítica de que a Existenzphilosophie se aproxima de uma Weltanschaung uma constatação do estado confusional em que se encontra o humano em sua medianidade.

Resultam duas consequências para a Existenzphilosophie: 1) no que se refere ao problema crítico do conhecimento, uma vez que postula a unidade entre sujeito e objeto, anula "em um só golpe" o problema. Conhecer seria uma "obviedade" inerente à forma unitária do mundo, embora, na prática, constate-se a dificuldade e a contradição;2) do ponto de vista da vida quotidiana, ou seja, do âmbito psicológico concreto das escolhas humanas, o reflexo é ainda mais grave, posto que Heiddeger afirma a autenticidade, mas simultaneamente a sua inacessibilidade, um paradoxo análogo ao paradoxo kantiano: pode-se afirmar, simultaneamente a existência do númeno e a sua incognoscibilidade? Ou seja, pode-se afirmar, simultaneamente, a autenticidade e a sua inacessibilidade?

Esta grande escola filosófica difunde-se e influencia importantes nomes da psicologia e da psiquiatria, entre os quais destacamos Karl Jaspers ${ }^{31}$, Ludwig Binswanger ${ }^{32}$, Medard Boss $^{33}$, Ronald Laing ${ }^{34}$, mas também a escola existencial norte-americana, chegando-nos pelas mãos da psicologia fenomenológico-existencial-humanista, ou terceira-força ${ }^{35}$.

Merleau-Ponty segue inicialmente o pensamento de Husserl, porém, termina por afirmar a impossibilidade de uma epoché total, criticando a redução transcendental por julgar que a fenomenologia deveria ater-se à filosofia da existência e da subjetividade, em sua condição de ser situado no "mundo-da-vida". O mais importante seria buscar sentido para a vida. A analítica existencial de Merleau-Ponty, sobre a experiência do outro e da subjetividade, faz-se a partir do seu ser-no-mundo, no contexto histórico, social e psicológico (CAPALBO, 2007).

\subsection{A Ontopsicologia e a Psicologia existencial-humanista}

O primeiro a usar o termo "Ontopsicologia", conforme relata Abraham Maslow ${ }^{36}$ na "Introdução à Psicologia do Ser", foi o psicólogo humanista norte-americano Anthony

\footnotetext{
31 1883-1969.

$321881-1966$

33 1903-1990.

34 1927-1989.

35 A psicologia do profundo, ou psicanálise, é considerada a "primeira força" da psicologia, enquanto o behaviourismo é considerado a "segunda-força". (MASLOW, 1999).

${ }^{36} 1908-1970$
} 
Sutich $^{37}$, fundador do "Journal of Humanistic Psychology" e co-fundador da "Association for Humanistic Psychology", para mostrar como a psicologia do seu tempo estava sob forte influência do existencialismo (MASLOW, 1999).

Em 1972, Joseph P. Ghougassian, Professor da Universidade da Califórnia, em San Diego, publicou o livro “Gordon W. Allport's Ontopsychology of the person”, onde analisou as contribuições de Gordon Allport ${ }^{38}$ à psicologia da personalidade. O termo "Ontopsicologia" foi utilizado em referência à psicologia de um Self, entendido como um projeto aberto em contínua auto-construção (GHOUGASSIAN, 1972).

Porém, embora já houvesse tais aproximações conceituais, só no início dos anos 70, temos a formalização teórica da "Ontopsicologia", com a publicação do texto "Ontopsicologia dell'Uomo" (MENEGHETTI, 1973).

Maslow aponta para um movimento multi-forme em direção à "identidade", destacando o trabalho muito mais empírico realizado na América do Norte por psicólogos como Gordon Allport, Carl Rogers ${ }^{39}$, Kurt Goldstein ${ }^{40}$, Erik Fromm ${ }^{41}$, Erik Erikson ${ }^{42}$, Rollo $\mathrm{May}^{43}$, entre outros, em relação ao trabalho desenvolvido pelos alemães, em particular, Heidegger e Jaspers, concluindo que, ainda que por vias diferentes, os filósofos europeus e os existencialistas norte-americanos têm um ponto de referência comum, a saber, o "colapso de todas as fontes de valores externos ao indivíduo" (MASLOW, 1999, p.14).

Para Maslow, o maior desafio é integrar na identidade humana concreta, o seu caráter de atualidade e potencialidade ou, como ele denomina, a "dupla natureza humana", sugerindo que a psicologia deveria focar justamente no desenvolvimento de técnicas integradoras, mas, ao mesmo tempo, tomar pé de que alguns problemas, por conta dessa dupla natureza, permaneceriam sempre insolúveis. Com isso, Maslow queria eliminar qualquer ilusão relativa a um ser humano puramente ideal, autêntico ou perfeito ou, por assim dizer, "divino", mas, simultaneamente, quer deixar aberta a via que aponta para a busca da atualização das potencialidades humanas: intelecto, intuição, criatividade, amor etc.

E tal tarefa não foi resolvida, a seu aviso, nem pelo behaviourismo de Watson ${ }^{44}$, nem por Freud, não obstante ele reconheça que cabe a Freud o mérito de ter nos fornecido uma visão sistêmica mais completa acerca da psicopatologia e da psicoterapia modernas. A tarefa

\footnotetext{
${ }^{37} 1907-1976$.

38 1897-1967.

39 1902-1987.

${ }^{40} 1878-1965$.

${ }^{41} 1900-1980$.

42 1902-1994.

43 1909-1994.

${ }^{44}$ Maslow pergunta: "What would an S-R man be like?"
} 
caberia à "terceira força", mas ela deveria abarcar questões relativas à vontade, à responsabilidade e seus corolários, a força e a coragem, bem como às dimensões da seriedade e profundidade da vida, do futuro, entre tantas outras. Porém, também a terceira força, a seu ver, não estava sendo capaz de dar respostas a tão variados e complexos desafios, que deveriam incluir também a refundação da filosofia da ciência (MASLOW, 1999).

Maslow conclui seu ensaio, originalmente apresentado no "Symposium on Existencial Psychology”, realizado em 1959 pela “American Psychological Association”, afirmando:

\begin{abstract}
Essas considerações apoiam minha esperança de que estamos testemunhando uma expansão da psicologia, não um novo "ismo" que pudesse se tornar uma antipsicologia ou uma anti-ciência. É possível que o existencialismo não enriqueça a psicologia. Pode ser também [que o existencialismo] seja um impulso adicional para o estabelecimento de um novo ramo da psicologia, a psicologia de um Self plenamente evoluído e autêntico e de seus modos de ser. Sutich sugeriu denominá-la de ontopsicologia. (MASLOW, 1999, p. 20).
\end{abstract}

São dramáticas e provocadoras, mas muito reais e atuais, as palavras finais do ensaio de Maslow, quando afirma que "cada vez mais, o que chamamos de normal em psicologia é na verdade a psicopatologia da média, tão não dramática e tão difundida que nós nem mesmo a notamos ordinariamente" e concluimos que "a maioria das pessoas experimenta ambas tragédia e alegria em diversas proporções. Qualquer filosofia que deixe uma delas de fora não pode ser considerada completa". (MASLOW, 1999, p.21)

De fato, só na década de 1970, com Antonio Meneghetti, houve um retorno à investigação deste Eu originário por meio de um pensamento comprometido com as idéias da "Crise", o que levou ao surgimento de uma abordagem conforme previsto por Maslow.

\title{
3 Conclusões
}

Nessa primeira etapa do percurso histórico-teleológico que conduziu ao nascimento da Ontopsicologia, foi explicitado o fio condutor que, partindo de Galileu Galilei, chega à Fenomenologia de Edmund Husserl e leva à busca de uma abordagem ao problema do homem e do conhecimento que pudesse atingir o mundo-da-vida, perpassando além disso os desdobramentos e as influências que o pensamento de Edmund Husserl trouxe para a Filosofia e Psicologia do século XX. O caminho de investigação do nexo ontológico empreendido por Antonio Meneghetti com a Ontopsicologia e a consequente resolução do paradoxo do Eu, consentindo a refundação crítica do conhecimento e das ciências em torno da retomada de uma consciência ontológica são precisamente as tarefas que trataremos em próximos estudos 
em busca de um pleno esclarecimento acerca das origens históricas e epistemológicas da Ontopsicologia.

\section{Referências}

AZEVEDO, E. O método ontopsicológico na clínica psicológica contemporânea. 2017. 329 f. Tese (Doutorado em Psicologia: Psicologia Clínica) - Programa de Estudos PósGraduados em Psicologia: Psicologia Clínica, Pontifícia Universidade Católica de São Paulo, São Paulo, 2017.

CAPALBO, C., A subjetividade e a experiência do outro: Maurice Merleau-Ponty e Edmund Husserl, Rev. abordagem gestalt. v.13 n.1 Goiânia jun. 2007.

CARR, D., Interpreting Husserl. Critical and Comparative Studies. Dordrecht: Martinus Nijhoff Publishers, 1987.

DESCARTES, R., Meditações metafisicas. São Paulo: Martins Fontes, 2011 (1641).

DODD, J., Crisis and Reflection; An Essay on Husserl's Crisis of the European Sciences. Dordrecht: Kluwer Academic Puclishers, 2004.

GHOUGASSIAN, J.P., Gordon W. Allport's Ontopsychology of the Person. New York: Philosophical Libraly, Inc., 1972.

HEELAN, PATRICK A., Husserl, Hilbert, and the Critique of Galilean Science. IN: SOKOLOWSKI, R. (org.), Edmund Husserl and the Phenomenological Tradition: Essays in Phenomenology (Studies in Philosophy and the History of Philosophy) Washington, D.C.: The Catholic University of America Press, 1989.

HEIDEGGER, M., Ser e Tempo. 6 ed. Petrópolis: Editora Vozes, 2006.

HUME, David. A Treatise of Human Nature (1740).

HUSSERL, E., Cartesianische Meditazionen und Pariser Vorträge. Dordrecht: Kluwer Academic Publishers, 2 ed., 1991. (1 ed. 1950)

Die Krisis der europäishen Wissenshaften und die transzendentale Phänomenologie. Eine Einleitung in die phänomenologische Philosophie. The Hague: Martinus Nijhoff, 1976. $\overline{(1987) .}$

Aufsätze und Vorträge (1911-1921), pp. 3-62: Philosophie als strenge Wissenschaft

Formale un Transzendentale Logik. Versuch einer Kritik der logischen Vernunft. Mit ergänzenden Texten. (1974)

KAHNEMAN, Daniel. \& TVERSKY, Amos. Maps of bounded rationality: a perspective on intuitive judgement and choice, Nöbel Prize Lecture, 2002; Experienced Utility and 
Objective Happiness: a moment-based approach In Choices, Values and Frames, New York, Cambrige University Press, 2000.

KOCKElmans, JOSEPH J., KISIEL, THEODORE J., Phenomenology and the Natural Sciences (Northwestern University Studies in Phenomenology and Existential Philosophy). Evaniston, Illinois: Northwestern University Press, 1970.

LOCKE, John. An essay concerning human understanding (1689). Hacket: Indianapolis, 1996.

MASLOW, A., Toward a Psichology of Being. 3. ed. New York: John Wiley \& Sons, Inc., 1999 (1a ed. D. Van Nastrand Company, 1968).

MENEGHETTI, A. Fisicità e Ontologia. Il rapporto critico tra fisica nucleare e Ontopsicologia, Roma: Psicologica Editrice, 2011.

MENEGHETTI, A. Manual de Ontopsicologia. 4 ed. Recanto Maestro: Ontopsicologica Ed., 2010 (trad. Ontopsicológica Editora Universitária, do original Manuale di Ontopsicologia, 1 ed.: 1995, 4 ed.: 2008)

MENEGHETTI, A. Ontopsicologia dell'Uomo. 1 ed. Roma: Centro di Terapia Ontopsicologica, 1973.

ZAHAVI, D. Husserl's Phenomenology. Stanford University Press, Stanford. 2003.

ZILLES, U. A crise da humanidade européia e a filosofia. Porto Alegre: EDIPUCRS, 1996. 